\title{
Discurso do Excelentissimo Senhor Presidente da República
}

DISCURSO DO EXCELENTISSIMY SENHOR PRESIDENTE DA REPÚBLICA, DOUTOR JUSCELINIO KUBITSCHIEK DE OLIVEIRA, ENCERRANDO A SESSÃO SOLENE DE ABERTURA DO $3^{\circ}$ CONGRESSO INTERNACIONAL DAS INSTITUIÇÕES DE CONTROLLE DAS FINANÇAS PÚBLICAS

"A Naçio Brasileira sente-se altamente desvanecida em poder acolher tantas personalidacles ilustres que, representando os órgãos superiores de contrôle das finanças públicas em seus respectivos paises, aqui vieram rell nir -se para expor idéias e impressões, confrontar experiências e debater os problemas emergentes no importante setor da fiscalização da execução orçamentária e da vigilância sôbre a arrecadação das rendas e a aplicação de despesa do Estado.

E uma das razões por que atribuímos especial significado à escolha do Rio de Janeiro para sede do III Congresso Internacional das Instituições Superiores da Contrôle das Finanças Públicas é que dispomos de uma formosa e severa tradição nzsse dominio. O Tribunal de Contas do Brasii. tal como atua até hoje, sob a forma de organização autônoma, foi na verdade contemporâneo da proclamação da República, e surgiu com a finalidade de dar corpo e expressão aos ideais republicanos referentes à exação e responsabilidades dos agentes da administração. A circunstância de sua origem histórica lhe assinalava, assim, as grandes linhas diretivas que iria desenvolver e ampliar no curso d’ tempo, a saber, a identificação com o interêsse público, a independência no julgamento, a autoridade inconirastável de suas decisões visando à legalidade dos atos financeiros, em conformidade com os principios básicos do regime democrático.

Relembro que os fundamentos e a estrutura do Tribunal de Contas se deveram à genial concepção de Rui BARBOSA, sábio, jurisconsulto e homem de Estado que o Brasil reverencia cono uma de suas figuras exponenciais. Foi êle então instituído como órgaão constitucional autônomo, de ação independente, colocado de premeio entre os Podêres Executivo e Legislativo, sem subordinação direta a qualq̣ıer dêles, e com ambos colaborandó para imprimir aos atos da administração financeira o desejado padrão de rigor e eficiência técnica. Através de uma experiência de quase setenta anos,

- Tribunal de Contas correspondeu amplamente aos propósitos que lhe inspiraraw a fundação, podendo ostentar invzjável fôlha de serviços ao apri- 
moramento de nossas instituições politicas. Os juizes que hoje tên assento no Tribunal de Contas, sob a presidência do Exmo. Sr. Ministro José Pereira Lira têm sabido continuar e exaltar as honrosas tradições dessa alta côrte, com os suprimentos de sua cultura e as reservas de seu acıridrado espírito público.

Como presidente da República, é motivo de profunda satisfação para miri comparecer à abertura desta assemb́léia internacional, a fim de render dos ilustres delegados que dela particjpam as homenagens do Govèrno do Brasil, e ao mesmo tempo exprinir-lhes os nossos votos para que do inter-

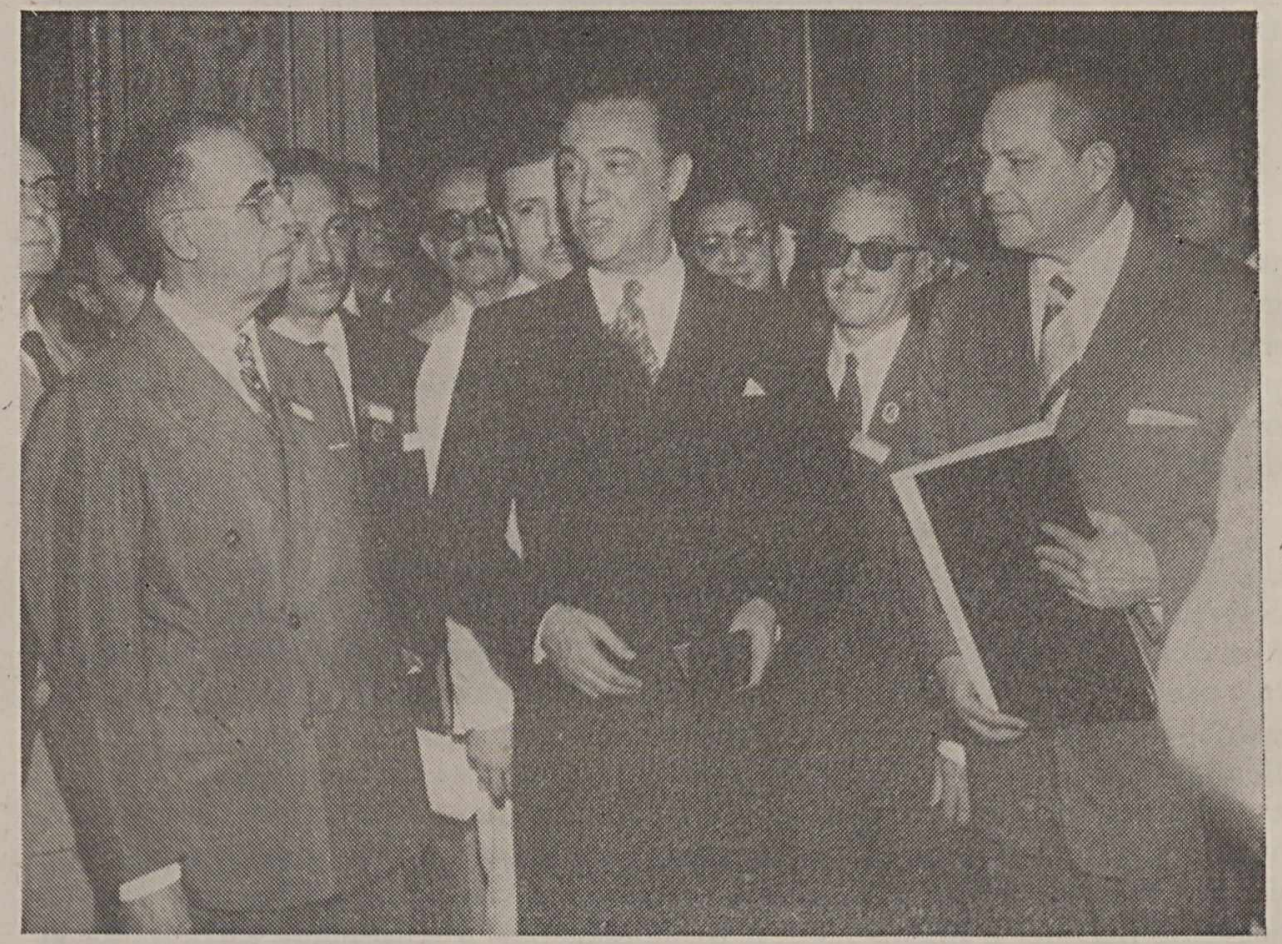

O Presidente da República, $\nu_{t}$. Juscelino Kubitscher, ladeado pelo Ministro Henrique Coutinho e pelo Ministro Presidente do Tribunal de Contas, Professor PEREIRA LiRA no momento em que proferia o seu discurso, na sessão inaugural do $I I I$ Congresso

câmbiu de idéias e pontos-de-vista resultem sugestões fecundas para um constante progresso em domínio tầ furdamental das atividades administrativas em todo o mundo. Bem sabeis, Senhores Congressistas, que em razão de vossas funções acompanhais tấo de perto, inclusive dêles participando, a evolução e os problemas da vida governamental en vossas Pátrias bem sabeis que vivemos uma época extraordinária e surpreendente, em que as conquistas da ciência e da técnica, as transformações de ordem ećnônica 
e os imperativos do bem-estar e da convivência social vão criando incessantemente novos valores, vão determinando situações novas, vão abrindo novos rumos e perspectivas. Todos os domínios da vida pública e particular sotrem o impacto dessas condiçõos e devem realizar um esfôrço mais ou menos profundo para elas se reajustarem, orientando-as num sentido útil e construtivo para a humanidade.

O mundo conturbado e dividido impõe às Nações que amam a liberdade o supremo dever de se unirem e reciprocamente colaboraren para acclerar o desenvolvimento econômico e cultural em tôdas as suas áreas, de modo que essa uniũo possa mobilizar sempre melhores e mais numerosos elementos de ordem material e de crdem espiritual para a adequaća preservação e defesa dos princípios que inspiram nossa civilização, baseada nos ideais de autodeterminação dos povos, de justiça social e de vida digna para todos os homens. Só assim será possivel às Nações livres fazer frente às exigências do mundo moderno, permanecendo sempre aptas a se sobrepor a tôdas à contingências no plano internacional, por mais difíceis que estas se apresentem. Foi inspirado neste pensamento, e interpretando as legitimas aspirações do povo brasileiro, que tive a honra de propor às Nações dêste Continente a idéia da Operação Pan-Americana, que se vai consubstânciando em ação política de grande amplitude e profundidade para colimação de um desiderato certamente da maior importância para os destinos da América e do mundo ocidental.

Acredito que estas observações têm pertinência numa reunião como esta, em que se congregam personalidades eminentes de tantos paises da Europa, da América e também dá Ásia, com o objetivo de confrentar informaçôes e dados de sua própria experiência em assunto que afeca, tão intimamente, ans problemas do govêrno $\epsilon$ da administração pública əm todos os seus aspectos. Atterdendo a ios imperativos mais legítimos de sua destinação histórica e igualmente às suas responsabilidades na comunidade das Nações do Ocidente, vem o Brasil lutando com vigor e decisão para superas os deszquilibrios da conjuntura econônica e atingir um grau de desenvolvimento compativel cotn suas imensas possibilidades de ordem materia! e com a expressão humana e cultural de sua população da ordem de sessenta milhões. Para isso, olhamos resolutamente para o futuro, sem esquecer as nossas tradições de um passado de lutas gloriosas pela liberdade e de trabalho árduo, paciente e silencioso na construção da Pátria. O futuro que buscamos há de ser para nós a transfiguração em novas e maiores iniciativas criacioras de um passado fecundo, que evocamos com respeito e orgulho como prólogo de nosso presente.

\section{Senhores Congressistas:}

Apresento-vos, em nome do Govêrno e do povo brasileiro, os nossos cumprimentos de hoas-vindas e espero aue esta assembléia se constitua em elo poderoso na corrente que une o Brasil às Nações amigas dêste e de outros Continentes, através do intercâmbio de idéias e da cooperação 
conjunta para o exame de problemas que a todos interessam. Estou certo de que os vossos trabalhos se corcarão dos resultados que é justo prever num encontro de tantos homens eminentes, cujos títulos os credenciam ao aprêço e à admiração gerais.

Com estas palavras, e agradecendo a alta distinção que me foi conferida, declaro instalado o III Congresso Internacional das Instituições Superiores de Contrôle das Finanças Públicas." 